Canadian Journal of Higher Education

Revue canadienne d'enseignement supérieur

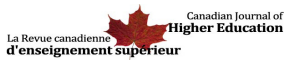

\title{
More Than a Pipeline Problem: Evaluating the Gender Pay Gap in Canadian Academia from 1996 to 2016
}

\section{Bessma Momani, Emma Dreher and Kira Williams}

Volume 49, Number 1, 2019

URI: https://id.erudit.org/iderudit/1060821ar

DOI: https://doi.org/10.7202/1060821ar

\section{See table of contents}

Publisher(s)

Canadian Society for the Study of Higher Education

ISSN

2293-6602 (digital)

Explore this journal

Cite this article

Momani, B., Dreher, E. \& Williams, K. (2019). More Than a Pipeline Problem: Evaluating the Gender Pay Gap in Canadian Academia from 1996 to 2016. Canadian Journal of Higher Education / Revue canadienne d'enseignement supérieur, 49(1), 1-21. https://doi.org/10.7202/1060821ar
Article abstract

This article measures gender pay gaps in Ontario's public post-secondary education sector from 1996 to 2016 using the Public Sector Salary Disclosure Data. We find gaps widening among all faculty ranks. Men were paid on average $2.06 \%, 2.14 \%$, and $5.26 \%$ more than their women colleagues for all employees, university teaching staff, and deans, respectively. We also conduct a Blinder- Oaxaca decomposition to measure the source of gendered salary differentials. Pay gaps persist during this time period despite controlling for the literature's most common explanations, including the "pipeline effect." Our results additionally imply that women's years of experience in academia do not mitigate the observed pay gaps. Suggestions for future research include increasing the scope of our study to factor in finer details such as labour productivity.
This document is protected by copyright law. Use of the services of Érudit (including reproduction) is subject to its terms and conditions, which can be viewed online.

https://apropos.erudit.org/en/users/policy-on-use/ 


\title{
More Than a Pipeline Problem: Evaluating the Gender Pay Gap in Canadian Academia from 1996 to 2016
}

\author{
Bessma Momani \\ University of Waterloo \\ Emma Dreher \\ Syracuse University \\ Kira Williams \\ Wilfrid Laurier University
}

\begin{abstract}
This article measures gender pay gaps in Ontario's public post-secondary education sector from 1996 to 2016 using the Public Sector Salary Disclosure Data. We find gaps widening among all faculty ranks. Men were paid on average $2.06 \%, 2.14 \%$, and $5.26 \%$ more than their women colleagues for all employees, university teaching staff, and deans, respectively. We also conduct a BlinderOaxaca decomposition to measure the source of gendered salary differentials. Pay gaps persist during this time period despite controlling for the literature's most common explanations, including the "pipeline effect." Our results additionally imply that women's years of experience in academia do not mitigate the observed pay gaps. Suggestions for future research include increasing the scope of our study to factor in finer details such as labour productivity.
\end{abstract}

\section{Résumé}

Cet article mesure les écarts de rémunération entre hommes et femmes actifs dans le secteur de l'éducation postsecondaire publique de l'Ontario entre 1996 et 2006 à l'aide des données de divulgation des salaires dans le secteur public. $\mathrm{Au}$ terme de cette étude, nous constatons que les écarts de rémunération 
s'agrandissent à tous les niveaux du corps professoral. Sur la période étudiée, les hommes étaient payés en moyenne respectivement, 2,06\%, 2,14\%, et $5,26 \%$ de plus que leurs collègues femmes pour tous les employés, le personnel enseignant des universités, et les doyens. Nous procédons également à une décomposition de Blinder-Oaxaca afin de mesurer la source des écarts de salaire différenciés selon le genre. Les écarts de rémunération persistent pendant cette période, malgré les principales explications fournies par la littérature, notamment "l'effet de pipeline." Nos résultats montrent en outre que les années d'expérience des femmes dans les universités n'atténuent pas les écarts de rémunération observés. Augmenter la portée de notre étude afin de prendre en compte des dimensions plus fines tels que la productivité au travail, est une des pistes futures de recherche qu'ouvrent cette analyse.

\section{Introduction}

Do gender pay gaps exist in Canadian society, and, if so, then how are they changing over time? Men, young people, and wealthier individuals tend to believe that enough policy attention has already been paid to gender equity, and $42 \%$ of women and $60 \%$ of men similarly assert that the government is currently doing enough to promote equal opportunities for women (Ipsos Public Affairs, 2017). Policy attention to pay inequity has not diminished. Indeed, the 2018 Federal Budget released by the Trudeau government in February 2018 focused specifically on issues of gender equality, including the aim of improving the economic inclusion of women and advancing the status of women across all facets of Canadian society (Government of Canada, 2018).

It has been over three decades since the Employment Equity Act was passed in 1987, yet addressing the persistent gender pay gap remains as relevant as ever. This evaluation is particularly timely in the Province of Ontario-the home of many of Canada's largest research universities, and the focus of additional, in-depth analysis-which marked the 3oth anniversary of its provincial Pay Equity Act in 2017. In the decades since the Act was passed, the gender pay gap has narrowed from $36 \%$ to $26 \%$-though there is still much work to be done in closing the gap altogether (Pay Equity Commission, 2018).

Our paper analyzes the existence and characteristics of gender pay gaps in one of our most progressive spaces: university campuses. Testing whether pay gaps exist, we find that sociocultural and socio-economic challenges that women face also exist in academia writ large-and, in some cases, to a greater extent than in other public-sector employment. Therefore, while some suggest that gender equity has been achieved, our research findings point to the persistence of gender gaps in representation and pay in higher administrative roles throughout Canadian universities.

The Canadian Association of University Teachers (CAUT; 2011) suggested that the pay gap in Canadian academia, as in the United States, has narrowed over time. Others have also noted that gains have been made toward gender equity within Canadian academia, but that women are consistently under-represented and underpaid (Eddy \& Ward, 2015; Bichsel \& McChesney, 2017). We examined these claims using new and comprehensive data.

We took an in-depth look at equal pay for equal work by gender in Ontario's academic institutions and found the gap widening among all faculty ranks. Looking at data between 1996 and 2016, we found significant ( $p<0.01$ ) gaps: men were paid on average $2.06 \%$, 
$2.14 \%$, and 5.26\% more than their women colleagues for all employees, university teaching staff, and deans, respectively. We also extended our analysis to look at pay gaps by institution and academic discipline, as well as changes in gaps over time. We also conducted a Blinder-Oaxaca decomposition to measure the source of gendered salary differentials. Given that we controlled for the literature's most common explanations, including the "pipeline" issue, these results were especially worrying; pay gaps increase as women faculty move up the echelons of the university system.

When we compared universities to other Ontario publicly funded institutions, ${ }^{1}$ academia was among the worst offenders in pay gap disparities-only behind health care and the judiciary. We thus find strong evidence to challenge the common perception that universities are closing gender pay gaps, raising doubts about the progressive nature of academic institutions, as discussed in this paper. Finally, and perhaps more troubling, we find these pay gaps are even more prominent among the top research-based universities, also known as U15.

\section{Policy Interventions as a Remedy?}

Strengthening legislative safeguards to ensure equal pay for equal work has been seen as one way to address the gender pay gap. Interestingly, however, the impacts of equal pay for equal work legislation have largely been mixed. Leveraging synthetic-control methods, McDonald and Thornton (2016) found that the 1987 Pay Equity Act in Ontario "failed to affect women's pay relative to men," and that while Quebec's Pay Equity Act was more successful, this success has been accompanied by "slightly reduced employment ratios" (p. 467). This is to say that, despite legislation aimed at addressing pay disparities among men and women, the most prominent Canadian interventions have not been able to close the gap fully-and the Ontario legislation had no discernible impact on gender pay gaps.

Conscious efforts to circumvent the requirements of the legislation-or willful ignorance to avoid having to make the necessary efforts to become and remain compliant-are counterproductive to the purported aims of the Pay Equity Act, and undermine its effectiveness. One survey undertaken in the early 1990 s of 27 private-sector firms in Toronto, Ontario, found that nearly $60 \%$ of surveyed firms "found pay equity to be a significant administrative burden" - with legislation failing to substantively improve the pay gap for women (McDonald \& Thornton, 1998, p. 201). ${ }^{2}$ Additionally, non-compliance or "manipulation of the requirements" of the legislation was evident in over one-third of firms surveyed. Observed non-compliance varied in severity, and while "ignorance or misunderstanding" was attributed to some cases, other cases presented showed non-compliance to be "clearly intentional" (p. 194). Another interviewee acknowledged that men and women do not see the same rate of progression with respect to pay bands.

Research on the implications of the Pay Equity Act at Ontario universities was similarly disappointing. Drawing on resources from the Council of Ontario Universities and the Ontario Confederation of University Faculty Associations-in addition to a survey completed between 1997 and 2000 of faculty at all major Ontario universities-McDonald and Thornton (2001) found that faculty at all Ontario institutions was classified as a "male job class." This classification is based on the Pay Equity Commission's guidelines, which would have taken into consideration characteristics such as "historical incumbency" of a given role alongside "gender stereotypes of the fields of work" when determining 
the job class assigned to all faculty at Ontario universities (Pay Equity Act, R.S.O. 1990, c. P.7, s. 1 (5)). As a result, institutions thus had "no obligations under the Pay Equity Act to adjust salaries of its female professors" (McDonald \& Thornton, 2001, p. 360).

Despite this, however, pay equity should apply here. While there is evidence that many institutions did provide salary adjustments for women faculty, these efforts were described as a "one-time event and no procedures for monitoring salary determination in the future were put in place" (p. 364). Furthermore, the legislation itself did not stipulate any reassessment of the job class after it was defined-meaning that universities were under no obligation to reassess job classifications even as the percentage of women faculty steadily increased in the years that followed. Despite evidence of improvement in the gender pay gap since the 1987 legislation was enacted, its effects have been modest at best. McDonald and Thornton (2001) noted that women faculty have likely been disadvantaged by the classification of all faculty jobs in Ontario as a singular male job class.

\section{Explaining the Absence of Equal Pay for Equal Work by Gender in Academia}

An interdisciplinary review of existing literature on the salary gap among women in higher academic administration revealed a number of theories, many of which hinge on the central argument that the gap in earnings for women in academia can often be explained by structural disadvantages within university settings, which result in career stagnation and women working in lower-paying academic fields. Other factors cited in the literature include productivity measures that tend to disadvantage women based on their contributions in the workplace.

\section{Previous Work on the "Gender Pay Gap" in Labour Economics}

A number of papers have analyzed the determinants of salary in academia, including gender, in the Canadian context. Warman, Woolley, and Worswick (2010) found persistent but declining earnings differentials between men and women who were full-time instructional staff in all Canadian universities between 1970 and 2001. Two detailed analyses of salary differentials at the University of Manitoba from 1993 to 2013 likewise found substantial gaps in a similar study group, which were mostly explained by differences in academic rank (Brown, Troutt, \& Prentice, 2011; Brown \& Troutt, 2017). These papers made use of more advanced ordinary least squares estimation and Blinder-Oaxaca decomposition, using age, gender, academic rank, and education as control variables. Three key limitations of these papers, however, was their inclusion of only full-time teaching staff, inability to track individuals across institutions, and lack of formal definition for occupational classification. We address all three of these issues in this paper. ${ }^{3}$ The Canadian Association of University Teachers (2018) identified a median wage gap between women and men in Canadian universities of approximately $10 \%$ or CAD $\$ 13,750$. The Academic Women's Association of the University of Alberta likewise identified substantial gendered wage differentials in Canadian universities by academic rank and minority status (AWA, 2018).

Although none of the above studies used Public Sector Salary Disclosure Data (PSSD) for their analysis, two further salary in academia studies did. Sen, Ariizumi, and DeSousa (2014) used these data to analyze the relationship between performance and salary for 
543 economics professors in 16 Ontario universities between 1996 and 2006. By contrast, Essaji and Horton (2010) made senior administrative labour their analytical object, determining the association of administrative staff salary increase between 1996 and 2006 using PSSD. While gender was therefore not the focus of either study, both found significant gender earnings differentials among economics professors and senior university administrative staff. We extend their findings by expanding our analysis to all university staff in Ontario-the home of many of Canada's largest research universities-using the PSSD from 1996 to 2016.

Our paper specifically tests the hypothesis of the (non-)existence of gender pay gaps amongst three groups: all post-secondary employees, university teaching staff, and deans. We expand this testing by analyzing the (non-)existence of pay gaps over time, by institution, and by discipline.

\section{Discrimination and Gendered Structural Inequalities}

The Canadian Association of University Teachers notes that the pay gap between men and women can, in many cases, be accounted for by variations in level of education, professional experience, current role/faculty rank, hours of work, age, and the presence of a collective agreement. CAUT (2011) acknowledges, however, that "overt discrimination" (p. 7) is also a major factor in perpetuating the pay gap. Several Canadian institutions have launched internal investigations to identify these pay gaps, with many instituting salary adjustments for women faculty they found to be underpaid (Bothwell, 2017). McMaster University instituted a \$3,515 salary adjustment in 2015 (McMaster University, 2015), while the University of Waterloo implemented its own salary adjustment in 2016 (Loriggio, 2016). Despite this, evidence shows that gender pay gaps still exist, including at those universities that have taken steps to rectify previous salary disparities.

Pay gaps are reinforced by what Kaplan and Tinsley (1989) refer to as the "pyramidal structure" that exists within administrative ranks in university settings, which has the tendency to disproportionately leave women "clustered at the bottom" (p. 18). As a result, many women experience career stagnations before they reach the director/dean level or above. Women faculty are "disproportionately worse off" (Ornstein \& Stewart, 1996, p. 474) in comparison to men-particularly at the assistant and associate levels. Men are more likely to be promoted when compared to women, while women "take longer to be promoted" in comparison (Ginther \& Hayes, 2003, p. 67). While these differences in promotion among men and women were noted as more substantial in the humanities than in the sciences, such evidence is particularly important given the role that rank plays with respect to salary.

Using data collected by the College and University Professional Association for $\mathrm{Hu}-$ man Resources (CUPA-HR) through their "Administrators in Higher Education Salary Survey," in addition to United States Census data, Bichsel and McChesney (2017) have also found that while gender gaps in representation are narrowing, the number of women in the highest academic roles has yet to reach parity with men. They also present evidence that, at the dean level, pay gaps widen when women move into increasingly senior roles. This is indicative of a broader institutional dynamic that remains discriminatory to women throughout the faculty pipeline, becoming more pronounced among those at the highest levels of administration. 
A final structural inequality which could explain the pay gap is the fact that, as rank in the hierarchy increases, higher positions including dean typically have greater discretion and negotiations for hiring. One disadvantage women may face in this situation is "intrafamily bargaining," where having a family may constrain one's ability to negotiate during hiring. Having a family may also account for why women accept lower pay: the existence of a market trade-off between pay and autonomy both within the public sector and between it and the private sector. In this context, it may be rational more often for a woman to accept lower pay in return for greater autonomy in having and supporting a family.

\section{A Problem in the Pipeline}

The literature on gender pay gaps often refers to a "pipeline problem" that exists within academia. The term pipeline refers to the "educational procession of undergraduate students through academia to tenured professorships" (van Anders, 2004, p. 511). The pipeline effect describes the tendency for women to leave academia earlier than men due to the intrinsic nature of a heavily male-dominated field. Wijesingha and Ramos (2017) explain this in terms of the "human capital theory," which holds that, based on existing measures of faculty productivity and years of experience, a woman's lack of career progression could be justified if she is less productive or less experienced than her colleagues (p. 55). Getting more women into academia should therefore lead to parity in gender representation and pay parity over time as more women embark on this career path; however, this is not happening. In one study, which included data collected on 500 graduate students, researchers found that women "self-select away from academia" as a result of "systemic barriers" that are primarily related to parenting and mobility (van Anders, 2004, p. 519). Ontario's Pay Equity Commission echoes the existence of these systemic barriers in their claim that the "existence of a gender wage gap is indicative of barriers facing women which prevent them from becoming fully integrated into the economic fabric of the province" (Pay Equity Commission, 2018, p. 1).

While many women persevere despite these and other challenges, some women also "opt out" or find themselves "pushed out" of academia as a result of these challenges (Mountz, 2016, p. 215). This is echoed in other studies as a "leaky-pipeline problem," where women opt out of academia because of challenges within university workplace settings (Valian, 2005, p. 207). Without addressing gender imbalances and structural inequities that have disadvantaged women over time, feeding the pipeline will not eradicate gender imbalances and inequities in both representation and pay. Achieving parity between men and women on a university's faculty listing is one thing, but paying them equally for work of equal value is another challenge completely. Increasing representation matters, but it does not solve the problem of equal pay for equal work.

While the pipeline problem is thus theoretically an important factor in altering gender pay gaps, few studies directly incorporate it into their models or use statistical analysis to address it. We provide a novel approach by explicitly accounting for the pipeline argument in our statistical modelling, providing one of the first measurements of its empirical relationship while enhancing the reliability of gender pay gap estimates.

One way to measure attrition is to analyze the distribution of women by academic rank as opposed to simply experience. If women tend to quit earlier due to a field's masculinity, then that should be reflected in their academic positions relative to men. While experi- 
ence matters, we measure it and the pipeline effect differently in our models. Specifically, we proxy the pipeline effect via academic rank and experience via an individual's number of years at a given institution in our data. We test these in regression modelling to identify and measure their statistical and substantive significance.

\section{Productivity Measures Favouring Research over Service and Teaching}

While collective agreements, which are prevalent among most Canadian academic institutions, ensure that base pay between men and women is the same on paper at each faculty level, in most cases other income supplements and promotion decisions are decided outside of these parameters-often disadvantaging women's earnings when compared to men at similar ranks throughout their careers. Using original data collected as part of an equal pay for equal work study undertaken at an American university from 1996-7, Carlin, Kidd, Rooney, and Denton (2007) presented statistical evidence based on a sample of 851 faculty, finding that while academic productivity "contributes significantly" to earnings of men within academia, it does not do so for women (p. 21). This is significant, because it highlights how measures that are traditionally leveraged to gauge productivity-such as book publications, grant funding, and awards-result in an increase in salary for men but are not given the same value for women faculty. There is also a suggestion that women in academia undertake more service and teaching roles that come at the expense of research performance, the former being less valued than the latter, and this explains the gender pay gap (Carlin et al., 2007, pp. 13, 22). Wijesingha and Ramos (2017) refer to this theory as the cultural taxation hypothesis, in which women's teaching and service work "inhibits productivity and ultimately leads to the denial of tenure and promotion" (p. 55).

Indeed, Fogg (2003) quotes one professor at an American university as saying that "students expect women to be more nurturing and available," while another added that "women are still not valued as highly as men, and our salaries reflect that" (n.p.). One professor explicitly made reference to the fact that "women are expected to do more service" (n.p.). Similarly, Carlin et al. (2007) noted that women in academia may be disadvantaged by excess service work, which negatively affects their productivity and the eventual salary increases associated with traditional productivity measures and promotion into more senior administrative roles. As such, we expect that women faculty would therefore be less likely to advance into dean-level positions given their propensity for teaching and service work, as these metrics have not traditionally been used to assess productivity and, in a related vein, promotion.

A critical limitation of our study is that we are unable to explicitly measure productivity differentials between men and women for teaching, research, or service in our modelling. This is due to the absence of such measures in the PSSD.

\section{Field of Study}

There is debate surrounding whether academic discipline and/or field of study explains the gender pay gap. However, this has been refuted in more recent studies. Studies published in 2001 and 2003 find that there are differences in pay gaps across disciplines. Leveraging data from the Survey of Doctorate Recipients from 1973 to 1997, Ginther 
(2001) found that there exists a "persistent salary gap" among men and women working in the sciences (p. 29). Leveraging data from this same survey from 1977 to 1995 , Ginther and Hayes (2003) found that, among those working in the humanities, the gap in salaries was "not significantly different from zero" (p. 67) - a finding that differs significantly from Ginther's earlier findings. The fact that there are more women working in the humanities, and that this field typically pays less than the sciences, are both offered as explanations as to why overall academic pay gaps exist.

Women are clustered into academic disciplines that are lower paying, and are at a disadvantage compared to STEM fields with better access to research funding propelling their careers forward. Funding invariably has a positive effect on higher earnings. To test these theories surrounding field of study and gender pay gaps, we utilized a statistical analysis of gaps by discipline. Based on existing literature, we expect that fields dominated by men will show evidence of more substantial pay gaps than those fields that are dominated by women. However, given the availability of research funding to women in male-dominated fields, we expect that their progression through the pipeline may be positively impacted by their access to research supports compared to those that exist in the humanities.

\section{Methodology}

To assess the gender pay gaps at Canadian universities, we analyzed three sets of quantitative data: the Government of Ontario's PSSD data from 1996 to 2016, Statistics Canada's University and College Academic Staff System-Full-time Staff (UCASS) 2016 data, and Statistics Canada's Workplace and Employee Survey data from 1999 to $2005 .{ }^{4}$ We also employed a Blinder-Oaxaca decomposition from 1996 to 2016 to measure the source of gender salary differentials by endowments, ${ }^{5}$ coefficients, and gender alone.

We conducted the major part of our analysis on PSSD. We specifically looked at gender pay gaps in the post-secondary education and the wider public sector using multiple modelling methods on the PSSD data from 1996 to 2016 (Government of Ontario, 2017). These data included the population of public sector employees whose employers paid CAD $\$ 100$, oooor more in the given year $(n=1,056,957)$. A summary of core variables for the post-secondary data can be found in Table 1.

While PSSD had information on employee first and last names, it lacked a variable for gender. We therefore predicted gender using R's gender package version 0.5.1 (CRAN, 2015). We matched provided first names using three methods, comparing names to those in the (1) U.S. Social Security Administration (SSA) records from 1932 to 2012; (2) U.S. Census from 1940 to 2010; and (3) Kantrowitz name corpus. We then selected the SSA method, since it successfully predicted the gender of the most observations: $70.1 \%$ (or 158,653 ) of post-secondary employees and $80.1 \%$ (or 846,767 ) of all public sector employees. We only continued analysis on employees with a predicted gender and removed all "seconded" employees. ${ }^{6}$

We attempted to ensure a balanced sample of the observable characteristics of men and women in order to reduce bias in our comparison using matching methods. We created and used measures of post-secondary institution and type, job category and type, number of years on the list at a given institution, and year as selection variables. As it turned out, however, our original sample was well-balanced and variations of nearest 
neighbour and optimal matching in R's MatchIt package, version 3.0.1, produced lessbalanced samples. This meant that our original sample suffered from relatively less selection bias than comparable matching procedures could generate. ${ }^{7}$

Table 1. Summary of Data used in Analysis-Post-secondary Education Employees in $P S S D, 1996-2016 *(n=158,099)$

\begin{tabular}{|c|c|c|c|c|c|c|}
\hline Variable & Description & $n$ & Mean & $\begin{array}{l}\text { Standard } \\
\text { Deviation }\end{array}$ & Skewness & Kurtosis \\
\hline year & Time salary was paid & 158,653 & 2010.44 & 4.50 & -0.84 & 0.24 \\
\hline sector & $\begin{array}{l}\text { Employee's sector; } \\
\text { colleges or universities }\end{array}$ & 158,653 & $\begin{array}{l}\text { University } \\
\text { [Mode] }\end{array}$ & NA & NA & NA \\
\hline name_last & Last name & 158,653 & NA & NA & NA & NA \\
\hline name_first & First name & 158,653 & NA & NA & NA & NA \\
\hline ln_salary_paid & $\begin{array}{l}\text { Natural logarithm of } \\
\text { salary paid }\end{array}$ & 158,653 & 11.77 & 0.22 & 1.39 & 2.71 \\
\hline employer & Named employer & 158,653 & $\begin{array}{l}\text { University } \\
\text { of Toronto } \\
\text { [Mode] }\end{array}$ & NA & NA & NA \\
\hline job_title & $\begin{array}{l}\text { Named position with } \\
\text { employer }\end{array}$ & 158,653 & NA & NA & NA & NA \\
\hline gender_int & Predicted gender & 158,653 & $\begin{array}{l}0.63 \\
\text { (Man) }\end{array}$ & 0.48 & -0.53 & -1.72 \\
\hline job_4dnoc2016 & $\begin{array}{l}\text { Occupation category, } \\
\text { National Occupational } \\
\text { Classification } 2016\end{array}$ & 158,653 & NA & NA & NA & NA \\
\hline name_int_rep & $\begin{array}{l}\text { Number of years name } \\
\text { has occurred on list for } \\
\text { given employer }\end{array}$ & 158,653 & 4.66 & $3 \cdot 52$ & 1.23 & 1.40 \\
\hline prof_rank* & $\begin{array}{l}\text { Academic rank of } \\
\text { instructor }\end{array}$ & 103,007 & $\begin{array}{l}3.5 \\
\text { (Associate } \\
\text { Professor) }\end{array}$ & 0.81 & -2.16 & $5 \cdot 77$ \\
\hline
\end{tabular}

Note. *Variable only included in analysis of university teaching staff.

We modelled gender pay gaps using three types of estimators and Huber-White standard errors: naive treatment effects, ${ }^{8}$ ordinary least squares, and differences-in-differences for all data from 1996 to 2016. All models used logged salary paid as the dependent variable and gender as an independent variable. We used the following control variables: year, sector, employer, job category, and the pipeline problem. Differences-in-differences models used gender and sector as factor variables to contrast universities with colleges. Again, one critical limitation of our study is the lack of variables measuring labour productivity in teaching, research, or service. We compared our results to similar models on UCASS and WES data in order to contrast our empirical findings in PSSD with alternative data sources. We assumed statistical significance beyond a 99\% confidence interval, and substantive significance wherever a result had a tangible impact on salary. We made all models, figures, and tables in $\mathrm{R}$ version 3.4.1. 
Our approach to generating a proxy variable for the pipeline problem worked as follows. We measured the intensity and representation of men and women in the academic pipeline by counting the number of years employed for each unique name at a given institution and year. So, for example, if an employee appeared in PSSD for the years 2009 to 2016 for the same university, then our proxy variable would measure their pipeline value as " 1 " in 2009, "2" in 2010, and so on, until "9" occurred in 2016. To do this, we created an initial list of unique names, which we further reduced by matching names with slight recording differences using Levenshtein (edit) distance. ${ }^{9}$ We then calculated the pipeline proxy variable's value for each unique name over time and institution.

\section{Findings}

We modelled gender pay gaps in post-secondary education between 1996 and 2016. We estimated pay gaps for all employees, university teaching staff, and deans for each year as well as the entire time period. We compared our results for 2016 against similar models in UCASS for all employees, university teaching staff, and deans, and for 1999 to 2005 against similar models in WES for all employees. We also estimated pay gaps by institution and academic discipline. We found significant, positive gender pay gaps, which increased over time for all employees and university teaching staff.

We conducted our general analysis on the gender pay gap in post-secondary education between 1996 and 2016 for three different groups: all employees, university teaching staff, and deans. We found statistically significant, positive gender pay gaps in both naive treatment effect and ordinary least squares estimators for all groups, as summarized in Tables 2 and 3. Estimated gaps were smaller in the ordinary least squares-based models than the naive treatment effects models. The former models estimated that men were paid about $2.06 \%$ more than women for all positions, $2.14 \%$ more for university teaching positions, and $5.26 \%$ more for dean positions.

Table 2. Gender Pay Gap in Post-secondary Sector for Those with a Salary Greater than CAD\$10o,ooo, by Group and Model Type, 1996-2016

\begin{tabular}{llrccc}
\hline Model & \multicolumn{1}{c}{ Group } & $\boldsymbol{n}$ & $\begin{array}{c}\text { Gender Pay } \\
\text { Gap (\%) }\end{array}$ & $\begin{array}{c}\text { Standard } \\
\text { Error (\%) }\end{array}$ & Adj. $\mathbf{R}^{2}$ \\
\hline Naive treatment effects & All employees & 158,653 & $4.51^{* * *}$ & 0.11 & 0.01 \\
Ordinary least squares & All employees & 158,653 & $2.06^{* * *}$ & 0.09 & 0.49 \\
Naive treatment effects & Deans & 7,501 & $4.60^{* * *}$ & 0.12 & 0.02 \\
Ordinary least squares & Deans & 7,501 & $5.26^{* * *}$ & 0.47 & 0.45 \\
Naive treatment effects & University teaching staff & 113,305 & $6.86^{* * *}$ & 0.60 & 0.01 \\
Ordinary least squares & University teaching staff & 113,305 & $2.14^{* * *}$ & 0.09 & 0.41 \\
\hline
\end{tabular}

Note. Statistical significance occurring beyond the following confidence intervals-**: $95 \%$; ** $99 \%$; and *** $99.9 \%$. Uses Huber-White standard errors.

We conducted more specific analysis to estimate pay gaps of all members of the Ontario Council of Universities, excluding Royal Military College of Canada. We found statistically significant, positive gender pay gaps in 16 out of 20 of these universities and 
no significant, negative pay gaps, as we present in Table 4. The five institutions with the largest gaps included University of Windsor (5.60\%), University of Ontario Institute of Technology (4.55\%), Queen's University (4.55\%), McMaster University (3.99\%), and York University (3.90\% ).

Table 3. Regression Results from Ordinary Least Squares Modelling of Determinants of Salary for Those with a Salary Greater than CAD\$1OO,OOO, 1996-2016

\begin{tabular}{llllllc}
\hline \multicolumn{1}{c}{ Model } & \multicolumn{2}{c}{ All Staff } & \multicolumn{2}{c}{$\begin{array}{c}\text { University Teaching } \\
\text { Staff }\end{array}$} & \multicolumn{2}{c}{ Deans } \\
\hline \multicolumn{1}{c}{$\begin{array}{c}\text { Independent } \\
\text { Variable }\end{array}$} & Coefficient & $\begin{array}{c}\text { Standard } \\
\text { Error }\end{array}$ & Coefficient & $\begin{array}{c}\text { Standard } \\
\text { Error }\end{array}$ & $\begin{array}{c}\text { Coefficient } \\
\text { Standard } \\
\text { Error }\end{array}$ \\
\hline (Intercept) & $3.48^{* * *}$ & 0.21 & $1.01^{* * *}$ & 0.25 & $-15.69^{* * *}$ & 1.19 \\
gender_int & $0.02^{* * *}$ & 0.001 & $0.02^{* * *}$ & 0.001 & $0.05^{* * *}$ & 0.005 \\
employer_int & $0.0005^{* * *}$ & 0.00003 & $0.003^{* * *}$ & 0.00003 & 0.002 & 0.0002 \\
name_int_rep & $0.04^{* * *}$ & 0.0002 & $0.04^{* * *}$ & 0.0002 & $0.03^{* * *}$ & 0.0006 \\
year & $0.004^{* * *}$ & 0.0001 & $0.005^{* * *}$ & 0.0001 & $0.01^{* * *}$ & 0.0006 \\
job_4dnoc2O16 & $-0.00002^{* * *}$ & 0.000001 & & & & \\
sector_int & $0.01^{* * *}$ & 0.0001 & & & $0.02^{* * *}$ & 0.0006 \\
prof_rank & & & $0.007^{* * *}$ & 0.0006 & & \\
$n$ & 158,653 & & 103,007 & & 7,501 & \\
Adj.R-squared & 0.45 & & 0.49 & & 0.41 & \\
\hline
\end{tabular}

Note. Statistical significance occurring beyond the following confidence intervals-*: $95 \%$; ** $99 \%$; and ${ }^{* * *}$ : $99.9 \%$. Uses Huber-White standard errors.

We also estimated pay gaps for university research disciplines from a cluster of 31 disciplines occurring over time in the data from 1996 to $2016 .{ }^{10}$ We found statistically significant, positive average gender pay gaps in 15 of these 31 disciplines and no significant, negative pay gaps. The five disciplines with the largest gaps included psychiatry (34.01\%), law (10.24\%), economics (9.53\%), accounting (8.60\%) and chemistry (7.10\%)-all of which were significantly larger than no gap, as seen in Table 5. The five smallest gaps occurred in geology (-6.55\%), sociology (-1.85\%), psychology (-0.60\%), biology (-0.28\%), and linguistics (-0.01\%) - none of which were significantly less than no gender pay gap. Linear regression of gender pay gaps by share of women in a given discipline in 2016 found a significant $(p<0.01)$, negative relationship: a $1 \%$ increase of women in a discipline was associated with an average $0.26 \%$ decrease in gender pay gaps.

We conducted additional analysis to estimate pay gaps for all employees, university teaching staff, and deans over time. We found that the gender pay gap for all employees significantly grew over time by about $0.11 \%$ per year $\left(R^{2}=0.64\right)$. This meant that men made $2.33 \%$ more than women on average by 2016 compared to -0.48\% in 1997. Figure 1 shows variation in the gender pay gap for all employees over time. The pay gap for university teaching staff likewise significantly grew over time by about $0.24 \%$ per year $\left(R^{2}=0.69\right)$. The pay gap for deans, by contrast, experienced no significant increase or decrease over time. 
Table 4. Gender Pay Gap in Post-secondary Sector for Those with a Salary Greater than CAD\$10o,ooo, by Group and Model Type, 1996-2016

\begin{tabular}{lrcc}
\hline University & $\boldsymbol{n}$ & Gender Pay Gap (\%) & Standard Error (\%) \\
\hline University of Windsor & 3,249 & $5 \cdot 59^{* * *}$ & 0.62 \\
University of Ontario Institute & 1,132 & $4.55^{* * *}$ & 0.98 \\
of Technology & & & \\
Queen's University & 5,262 & $4.53^{* * *}$ & 0.56 \\
McMaster University & 7,733 & $3.98^{* * *}$ & 0.47 \\
York University & 9,086 & $3.90^{* * *}$ & 0.38 \\
University of Toronto & 30,984 & $3.69^{* * *}$ & 0.23 \\
University of Western Ontario & 9,017 & $3.28^{* * *}$ & 0.47 \\
Brock University & 3,271 & $3.25^{* * *}$ & 0.46 \\
University of Ottawa & 9,733 & $2.53^{* * *}$ & 0.29 \\
Lakehead University & 1,837 & $2.38^{* * *}$ & 0.62 \\
Algoma University & 249 & 2.22 & 1.58 \\
University of Waterloo & 7,015 & $1.60^{* * *}$ & 0.42 \\
Wilfrid Laurier University & 4,900 & $1.58^{* * *}$ & 0.46 \\
Carleton University & 6,535 & $1.17^{* * *}$ & 0.32 \\
Laurentian University & 3,095 & $1.11^{*}$ & 0.50 \\
Ryerson University & 8,897 & $0.69^{*}$ & 0.31 \\
Trent University & 2,736 & 0.50 & 0.63 \\
University of Guelph & 8,784 & 0.22 & 0.30 \\
Nipissing University & 1,033 & -0.76 & 1.09 \\
Ontario College of Art \& & 618 & -1.68 & 1.45 \\
Design University & & & \\
\hline
\end{tabular}

Note. Statistical significance occurring beyond the following confidence intervals-**: $95 \%$; ** $99 \%$; and ***: 99.9\%. Uses Huber-White standard errors.

We extended our analysis to UCASS and WES using relatively similar populations. We compared gender pay gaps for all university employees, university teaching staff, and deans, regardless of salary, in Ontario for 2016. We estimated the following statistically significant gaps using naive treatment effect estimation: $11.20 \%$ for all employees (PSSD: $6.48 \%$ ), $10.51 \%$ for all university teaching staff (PSSD: 6.74\%), and 9.42\% for deans (PSSD: 10.49\%). Using one-tailed t-tests, we found that UCASS's gender pay gap estimates were significantly larger for all employees and university teaching staff than those from PSSD; contrastingly, we found no statistical difference between UCASS and PSSD gender pay gaps for deans.

We applied Blinder-Oaxaca decomposition to see how the observed salary differences by gender could be explained by differences in endowments, group coefficients, and gender alone. Of an observed $-\$ 5,699.90$ salary difference between women and men, the $\$ 2,755.77$ (or $48 \%$ ) of unequal pay for equal work was the result of different variable endowments between men and women. 
Table 5. Gender Pay Gap in Post-secondary Sector for Those with a Salary Greater than CAD\$10o,0oo, by Discipline, 1996-2016

\begin{tabular}{|c|c|c|c|}
\hline Discipline & $\mathrm{n}$ & Gender Pay Gap (\%) & Standard Error (\%) \\
\hline Psychiatry & 87 & 34.01 & $5 \cdot 33$ \\
\hline Law & 1126 & 10.24 & 1.06 \\
\hline Economics & 943 & $9 \cdot 54$ & 1.15 \\
\hline Accounting & 470 & 8.60 & 2.06 \\
\hline Chemistry & 706 & 7.10 & 1.45 \\
\hline Physics & 937 & 6.87 & 0.97 \\
\hline Genetics & 182 & 6.16 & 0.35 \\
\hline Architecture & 234 & 6.02 & 2.00 \\
\hline Biochemistry & 267 & 5.64 & 2.04 \\
\hline Mathematics & 946 & $4 \cdot 38$ & 0.92 \\
\hline Kinesiology & 267 & 4.05 & 1.62 \\
\hline Computer Science & 646 & 3.68 & 1.39 \\
\hline Physiology & 285 & 3.66 & 2.49 \\
\hline Business & 2991 & $3 \cdot 52$ & 0.84 \\
\hline History & 867 & 3.24 & 0.90 \\
\hline English & 1192 & 2.96 & 0.72 \\
\hline Pharmacy & 508 & 2.92 & 1.48 \\
\hline Anthropology & 393 & 2.91 & 1.42 \\
\hline Environmental Science & 756 & 2.76 & 1.08 \\
\hline Communications & 718 & 2.69 & 1.11 \\
\hline Medicine & 1632 & 2.55 & 1.26 \\
\hline Political Science & 832 & 1.99 & 1.05 \\
\hline Engineering & 2926 & 1.14 & 0.80 \\
\hline Music & 398 & 0.91 & 1.13 \\
\hline Philosophy & 721 & 0.59 & 1.42 \\
\hline Geography & 541 & 0.00 & 1.03 \\
\hline Linguistics & 395 & -0.15 & 1.05 \\
\hline Biology & 919 & -0.28 & 0.92 \\
\hline Psychology & 1007 & -0.60 & 0.94 \\
\hline Sociology & 708 & -1.85 & 1.04 \\
\hline Geology & 129 & -6.55 & 3.59 \\
\hline
\end{tabular}

Note. Statistical significance occurring beyond the following confidence intervals-**: $95 \%$; ** $99 \%$; and ***: 99.9\%. Uses Huber-White standard errors. 


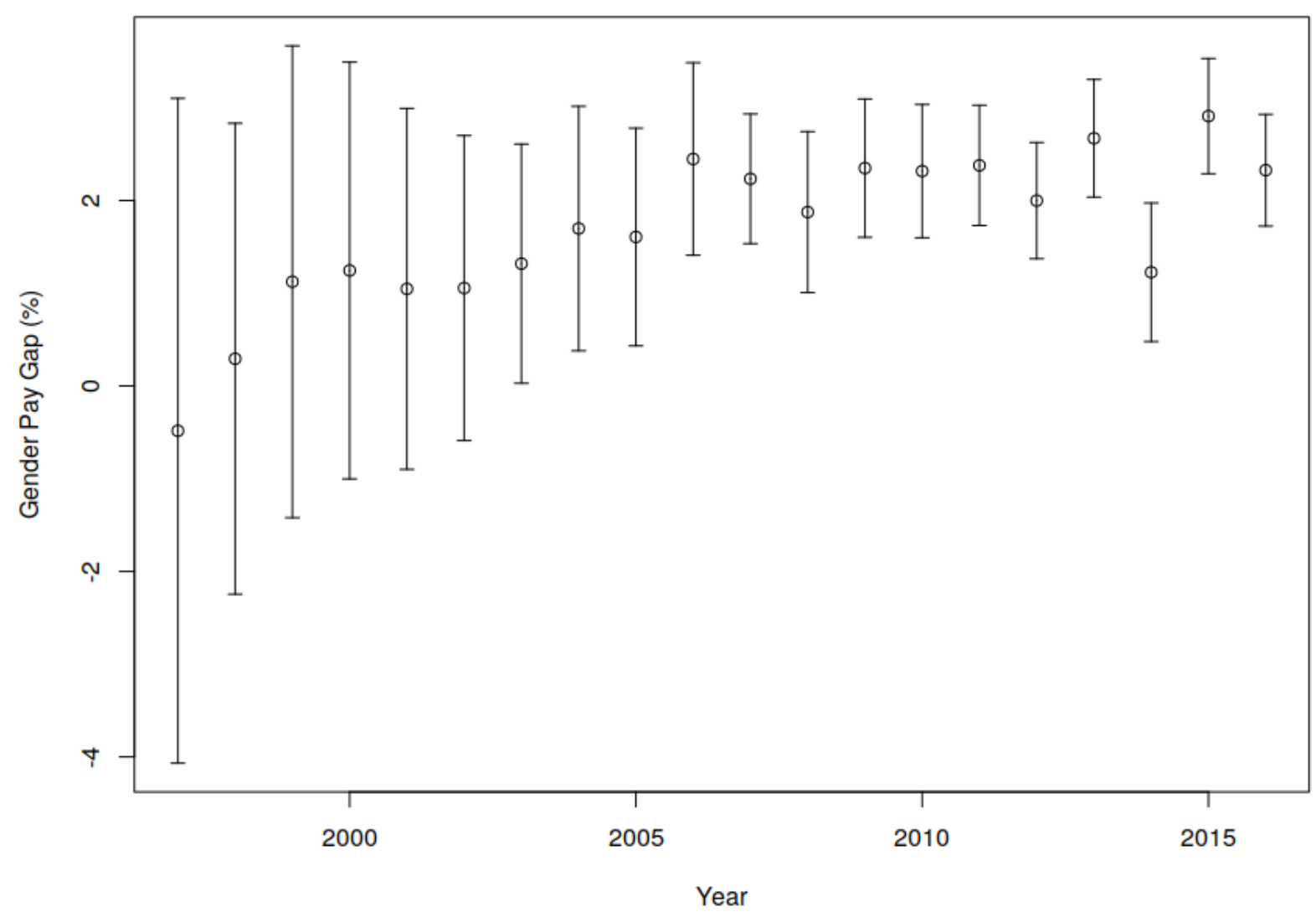

Note. Open circles: mean gender pay gap; bars: mean 99\% confidence interval.

Figure 1. Gender Pay Gap in Post-Secondary Education in Ontario All Employees, by Year, 1997 to $2016(n=20)$

The pipeline effect, in particular, was the most prominent endowment gap, accounting for $\$ 3,207.31$ (or $56 \%$ ) of salary differentials by gender alone. Differences in coefficients by gender accounted for about $40 \%$ of salary differentials, with the remaining $12 \%$ of unequal pay for equal work being explained by gender alone.

We found mostly parallel results for university teaching staff and deans. One notable difference, however, were which endowments affected gendered salary differentials among deans. Whereas the pipeline effect was most important for all staff and university teachers, the three largest endowment effects for deans were post-secondary sector (i.e., college or university), salary year, and the pipeline effect. Salary differences by gender were especially higher for deans in universities and those earlier in time.

We generated a comparable sample in WES looking at all sampled employees' education and health in Canada from 1999 to 2005. Using the same model structure including controls as for PSSD, we found a gender pay gap of about 6.21\% (PSSD for the same group: $6.47 \%$ ). Using a one-tailed t-test, we found no significant difference between WES' gender pay gap estimate and that from PSSD. 


\section{Discussion}

With respect to established theories on gender pay gaps in academia, and where appropriate proxy variables were available, our analysis generally supported previous causal hypotheses. Even with many of these factors, especially the pipeline problem, taken into account, gender pay gaps persisted across the board. Combined with $R^{2}$ values between 0.4 and 0.7 for most models, this indicated that our analysis probably missed some additional causes of gender pay gaps in academia. Our findings generally supported structural inequality approaches where possible, finding significant $(p<0.01)$ increases in gender pay gaps by professional experience, academic rank, and age. Correspondingly, our results support "pyramidal" models of discrimination, whereby gender pay gaps generally increase with position seniority.

Our models also gave strong evidence of the pipeline effect via the pipeline proxy variable. ${ }^{11}$ For all university employees in 2016 , for example, each additional year in the pipeline corresponded to an average $3.4 \%$ increase over previous pay. Since women had fewer years in the pipeline than men on average (5.25 versus 6.36 years in 2016), this effect meant that women generally received less pay than men; this outcome, however, failed to remove gender-specific effects. Our analysis also found empirical support for differences between fields of study, and, in another model, resulted in STEM disciplines having significantly larger $(p<0.01)$ gaps than other disciplines.

Overall, given the relatively stable and significant increase in gaps over time for all employees, our findings lend evidence to the relative ineffectiveness of policy intervention. Even if interventions were effective between 1996 and 2016, their impacts remained smaller than gender pay gap increases. This implies that policy has yet to effectively address gender pay gaps. This ineffectiveness may be due, in part, to the job classifications created at universities at the time the Pay Equity Act was established. Since university faculty were classified as a singular, male job class (McDonald \& Thornton, 2001)-and a reassessment has not been legislatively required in the years since-universities have not been legally obligated to uphold the key principles of the legislation, assuming they would have been effective if implemented. Despite this lack of legal obligation, many universities have instituted policies and procedures to "level the playing field" between men and women faculty; however, our results suggest these efforts have been unsuccessful at closing the gender pay gap. We were unable to test the following causal hypotheses found in the literature: education, work hours, unionization, and productivity-reward gaps.

Our findings were broadly consistent with those of previous studies. As previously noted, studies analyzing gender earning differentials have all found that women earned less on average than men (Warman et al., 2010; Brown \& Troutt, 2017; Essaji \& Horton, 2010). These papers estimated higher earnings differentials than our results indicated, with men earning anywhere from about $3.7 \%$ to over $12 \%$ more than women in a number of different contexts. As with these papers, our findings indicate that most of the salary differences between men and women in post-secondary education can be accounted for by different factor endowments, reflecting systemic discrimination against women (Brown \& Troutt, 2017). Chief among these factors was the pipeline effect, which indicates that women may be structurally impeded from reaching higher positions in the university hierarchy. 
Our results inform us of the following additional findings, at least in the context of Ontario from 1996 to 2016. First, there was a pipeline problem, and its effects remain substantial as late as 2016. In 2016 for all employees, as in most cases, the pipeline problem's impact was associated with men making about $3.7 \%$ more than women in the same jobs at the same institution. This effect's contribution to gender-based discrimination was thereby larger than all unaccounted-for gender-specific effects (about 2.3\%). These findings further imply a key result: while the pipeline problem did exist and has affected women in academia, gender pay gaps separate from the problem persisted, and so the pipeline problem alone could not account for the observed gaps. This is a major finding, as it disproves the popular pipeline theory, which asserts that more women moving through the pipeline would lead to eventual gender equity. This means that there is more to the story of gender discrimination in this case than simple differences than length of time in the academic pipeline. This finding could signal-similar to work presented by other scholars in the field-the role that unconscious bias plays in determining women's career success in both their promotion through the pipeline and their resultant earnings.

Second, deans were significantly different from other positions in terms of the effects of gender discrimination. Even accounting for other effects, including the pipeline problem, pay gaps specifically doubled for women who were deans compared to men. Although this gap did not significantly increase over time, it remained relatively high. Similar findings in UCASS supported this particular result in PSSD. UCASS, in fact, generally showed even higher gender pay gaps in comparable models to PSSD, suggesting that our results were relatively conservative. Such evidence supports existing work in this field, which has shown that the gender pay gap at the rank of dean presents the only case where the gap widens as women progress into more senior academic roles (Bichsel \& McChesney, 2017). Given the attention that has been paid to increasing gender parity in the highest echelons of academia at many universities, the fact that women are likely to experience the highest pay gap of their careers when they reach the dean level may indicate that while universities are promoting women-perhaps for the sake of having a woman in senior faculty administration-they are failing to compensate them comparatively to men at that same level. Again, this is evidence of gender discrimination within the faculty pipeline-discrimination that worsens as women advance through their careers.

Third, field of study mattered. While patterns of gender pay gaps varied highly by discipline, our available evidence provided initial results for identifying the worst offenders, as well as for comparing STEM to other fields. In this case, though STEM disciplines exhibited higher gender pay gaps, this effect $(\sim 1-2 \%)$ itself was not large enough to explain differences between disciplines more generally. So, for example, while we know that engineering generally had higher gender pay gaps than social science, economics showed a much larger gap than engineering. We found that although disciplinary gaps remained in 2016, increasing participation of women in a discipline was significantly associated with reductions in the average gender pay gap.

\section{Analysis and Conclusion}

As we reflect on Ontario's progress since the Pay Equity Act was introduced in 1987, it is imperative to acknowledge that there remains room for improvement. While policy has been directed towards encouraging or mandating equal pay for equal work, our results indicate that the gender pay gap among university deans in terms of percentage earnings 
may in fact be worsening despite these efforts. Given an increased focus on the empowerment of women-and gender equity more broadly - both in Canada and around the world, the results of this study convey that there is still much work to be done to address the gender pay gaps which continue to persist within Canadian universities.

We acknowledge that many universities have formed committees and launched investigations surrounding gender equity in their own institutions; however, investment in further research that builds on the findings presented in this study would inform more effective approaches to closing the gender gap in the years to come. While our study showed that the pipeline theory alone cannot account for gender pay gaps, future research that compares finer details, such as credentials and publication histories of all women and men deans at Canadian universities, could test this finding. Further research regarding pay gaps between fields of study could also prove beneficial, informing institutional approaches to addressing these gaps, particularly in STEM.

With an increased focus on the advancement of women in all facets of Canadian society, there is healthy societal discussion of these issues. Nevertheless, Canadians' perceptions of the extent of the gender gap-and the relative (in)effectiveness of policy interventions meant to address it-will impede future efforts to close the gap. Acknowledging the existence of a problem in the pipeline, be it caused by implicit bias or the structural makeup of universities themselves, is a crucial first step at the institutional level. From a legislative perspective, it is evident that current policies need to be evaluated and improved in light of changes that have occurred in the Canadian workforce over the last three decades.

\section{Notes}

1. Other public sector industries analyzed included Crown agencies, hospitals and boards of public health, Hydro One and Ontario Power Generation, the judiciary, Government of Ontario ministries and legislative assembly, municipalities, other public sector employees, and public (primary and secondary) school boards.

2. To this end, an anonymous reviewer noted the challenges associated with efforts to remedy gender pay gaps that are made in "good faith" and their likelihood of posing an administrative burden while failing to achieve pay equity goals in a timely manner. They also noted resistance that such efforts may face, particularly if salaries of men were cut to increase the salaries of women, or if less productive scholars were rewarded equally to those who are highly productive.

3. Specifically, we include all university staff from the Public Sector Salary Disclosure data, track individuals from institution to institution via their reported names, and use Employment and Social Development Canada's National Occupational Classification System to classify job positions. For more information on the latter, see Employment and Social Development Canada (2018).

4. For source data, produced data and code script for producing all results, see https:// sites.google.com/view/kirandreawilliams/published-data.

5. Different factor endowment refers to differences in the starting positions of men and women and how those differences impact salary differentials. If a group generally begins in a better position (e.g., more education, more wealth, better health), then we would expect that group to have higher success on average, and therefore higher pay than other groups. 
6. In PSSD, a name may occur twice for the same year if they were "seconded" to another public sector employer. Seconded observations are effectively duplicates except for their additional employer. We removed these observations $(n=627)$ in order to remove their statistical bias.

7. Conducting nearest neighbour matching on gender by sector, employer, discipline, occupational classification, year, and experience increased mean distance from 0.5925 in the initial sample to 0.7271 in the matched sample-meaning a reduction in overall balance.

8. Naive treatment effects represent the most basic mean treatment effects-that is, the mean differences between each study group with no other control variables (Morgan \& Winship, 2007). These form the baseline estimate of treatment effects of the study groups. We include them in our analysis for contrast with more robust methods.

9. This was necessary due to inconsistencies in recording names in PSSD. As it turned out, the same name over different years might be differently recorded (e.g., "Jane Doe-Hill" could become "Jane Doe Hill"). Some names also experienced minor errors in recording (e.g., the omission of a letter). By using editing distance, we were able to identify and match such names, thereby more accurately measuring the pipeline problem.

10. Disciplines included accounting, anthropology, architecture, biochemistry, biology, business, chemistry, communications, computer science, economics, engineering, English, environmental science, genetics, geography, geology, history, kinesiology, law, linguistics, mathematics, medicine, music, pharmacy, philosophy, physics, physiology, political science, psychiatry, psychology, and sociology.

11. Pipeline effect is proxied here using years of experience.

\section{References}

Academic Women's Association of the University of Alberta (AWA). (2018). Equity at Canadian universities: National, disaggregated and intersectional data. Retrieved from https://uofaawa.wordpress.com/awa-diversity-gap-campaign/the-diversity-gap-atcanadian-universities-in-2018/

Bichsel, J., \& McChesney, J. (2017). Women's equity in higher education administration: Pay and representation. College and University Professional Association for Human Resources. Retrieved from https://www.higheredtoday.org/2017/02/24/ womens-equity-higher-education-administration-pay-representation/

Bothwell, E. (2017, May 17). Canadian university hikes female salaries to remove gender pay gap. Times Higher Education (THE). Retrieved from https://www. timeshighereducation.com/news/canadian-university-hikes-female-salaries-removegender-pay-gap

Brown, L., \& Troutt, E. (2017). Sex and salaries at a Canadian university: The song remains the same or the times they are a changin'? Canadian Public Policy, 43(4), 24626o. https://doi.org/10.3138/cpp.2016-047

Brown, L., Troutt, E., \& Prentice, S. (2011). Ten years after: Sex and salaries at a Canadian university. Canadian Public Policy, 37(2), 239-255. https://doi.org/10.3138/ cpp.37.2.239 
Canadian Association of University Teachers (CAUT). (2011). The persistent gap: Understanding male-female salary differentials amongst Canadian academic staff (CAUT Equity Review No. 5).

Canadian Association of University Teachers (CAUT). (2018). 2.1 Average and median salaries of full-time university teachers by rank and gender, 2016-2017. Retrieved from https://www.caut.ca/content/21-average-and-median-salaries-full-time-universityteachers-rank-and-gender-2016-2017

Carlin, P., Kidd, M., Rooney, P., \& Denton, B. (2007). The academic gender earnings gap: The effect of market salaries and imperfect productivity measures. IDEAS Working Paper Series from RePEc; St. Louis. https://ideas.repec.org/p/iup/wpaper/wp200703. html

Comprehensive R Archive Network (CRAN). (2015). Package "gender.” Retrieved from https://cran.r-project.org/web/packages/gender/gender.pdf

Eddy, P. L., \& Ward, K. (2015). Lean in or opt out: Career pathways of academic women. Change: The Magazine of Higher Learning, 47(2), 6-13. doi:10.1080/0009138 3.2015.1018082

Employment and Social Development Canada. (2018). Welcome to the National Occupational Classification 2016. Retrieved from http://noc.esdc.gc.ca/English/noc/ welcome.aspx?ver $=16$

Essaji, A., \& Horton, S. (2010). Silent escalation: Salaries of senior university administrators in Ontario, 1996-2006. Higher Education, 59(3), 303-322. https://doi. org/10.1007/s10734-009-9249-2

Fogg, P. (2003, April 18). The gap that won't go away: Women continue to lag behind men in pay; the reasons may have little to do with gender bias. The Chronicle of Higher Education, 49(32). https://www.chronicle.com/article/The-Gap-That-Wont-Go-Away/ 12613

Ginther, D. K. (2001). Does science discriminate against women? Evidence from academia, 1973-97. IDEAS Working Paper Series from RePEc; St. Louis. https://ideas. repec.org/p/fip/fedawp/2001-2.html

Ginther, D. K., \& Hayes, K. J. (2003). Gender differences in salary and promotion for faculty in the humanities 1977-95. The Journal of Human Resources, 38(1), 34-73. doi:10.2307/1558755

Government of Canada, Department of Finance. (2018, February 27). Budget 2018. Retrieved from https://www.budget.gc.ca/2018/docs/plan/toc-tdm-en.html

Government of Ontario. (2017). Public sector salary disclosure. Retrieved from https://www.ontario.ca/page/public-sector-salary-disclosure

Ipsos Public Affairs. (2017). Global views on women's equality-Ipsos survey. Retrieved from https://www.ipsos.com/sites/default/files/2017-01/Women_and_ gender_equality.pdf

Kaplan, S., \& Tinsley, A. (1989). The unfinished agenda: Women in higher education administration. Academe, 75(1), 18-22. doi:10.2307/40249780 
Li, P. S. (2012). Differences in employment income of university professors. Canadian Ethnic Studies, 44(1), 39-48. doi:10.1353/ces.2012.0012

Loriggio, P. (2016, August 4). University of Waterloo boosts female faculty pay after wage gap uncovered. The Globe and Mail. Retrieved from https://www.theglobeandmail. com/news/national/university-of-waterloo-boosts-female-faculty-salaries-after-genderpay-gap-found/article31272503/

McDonald, J. A., \& Thornton, R. J. (1998). Private-sector experience with pay equity in Ontario. Canadian Public Policy/Analyse de Politiques, 24(2), 185-208. doi:10.2307/3551773

McDonald, J. A., \& Thornton, R. J. (2001). Comparable worth in academe: Professors at Ontario universities. Canadian Public Policy/Analyse de Politiques, 27(3), 357-373. doi:10.2307/3552474

McDonald, J. A., \& Thornton, R. (2016). Have pay equity laws in Canada helped women? A synthetic-control approach. American Review of Canadian Studies, 46(4), 452-473. doi:10.1080/02722011.2016.1265568

McMaster University. (2015). An analysis of gender equity in MUFA faculty salaries. Retrieved from https://www.mcmaster.ca/vpacademic/documents/MUFA\%20 Gender\%20Salary\%20Gap\%20Analysis_May\%202015.pdf

Morgan, S., \& Winship, C. (2007). Counterfactuals and causal inference: Methods and principles for social research. Cambridge, England: Cambridge University Press.

Mountz, A. (2016). Women on the edge: Workplace stress at universities in North America. The Canadian Geographer / Le Géographe canadien, 6o. doi:10.1111/cag.12277

Ornstein, M., \& Stewart, P. (1996). Gender and faculty pay in Canada. The Canadian Journal of Sociology / Cahiers canadiens de sociologie, 21(4), 461-481. doi:10.2307/3341526

Pay Equity Commission. (2018). 2018-19 gender wage gap grant program guidelines. Retrieved from http://www.payequity.gov.on.ca/en/DocsEN/2018-19\%20GWGGP\%20 Program\%20Guidelines\%20EN.pdf

Sen, A., Ariizumi, H., \& DeSousa, N. (2014). Evaluating the relationship between pay and research productivity: Panel data evidence from Ontario universities. Canadian Public Policy, 4O(1), 1-14. doi:10.3138/cpp.2012-065

Valian, V. (2005). Beyond gender schemas: Improving the advancement of women in academia. Hypatia, 2O(3), 198-213. doi:10.1111/j.1527-2001.2005.tbo0495.x

van Anders, S. M. (2004). Why the academic pipeline leaks: Fewer men than women perceive barriers to becoming professors. Sex Roles, 51(9-10), 511-521. doi:10.1007/ s11199-004-5461-9

Warman, C., Woolley, F., \& Worswick, C. (2010). The evolution of male-female earnings differentials in Canadian universities, 1970-2001. Canadian Journal of Economics, 43(1), 347-372. https://doi.org/10.1111/j.1540-5982.2009.01575.x 
Wijesingha, R., \& Ramos, H. (2017). Human capital or cultural taxation: What accounts for differences in tenure and promotion of racialized and female faculty? Canadian Journal of Higher Education, 47(3), 54-75.

\section{Contact Information}

Bessma Momani

Department of Political Science

University of Waterloo

bmomani@uwaterloo.ca

Bessma Momani is Professor at the Balsillie School of International Affairs and the University of Waterloo. She is also a 2015 Fellow of the Pierre Elliot Trudeau Foundation (PETF) and the author of the Demographic Dividend report published by the Centre for International Governance and Innovation and PETF.

Emma Dreher is a PhD student in political science at Syracuse University's Maxwell School. She previously studied at the Balsillie School of International Affairs where she earned her Master's in International Public Policy.

Kira Williams has a PhD from Wilfrid Laurier University's Department of Geography and is a post-doctoral fellow at the Balsillie School of International Affairs and the University of Waterloo. 